\title{
\begin{tabular}{l|l} 
Article & $\begin{array}{l}\text { Creative Misuse as Resistance: Surveillance, } \\
\text { Mobile Technologies, and Locative Games }\end{array}$
\end{tabular}
}

\section{Jason Farman}

University of Maryland, US.

jasonfarman@gmail.com

\begin{abstract}
By focusing on locative, mobile games that utilize GPS tracking in playful ways-from games such as geocaching and GPS::Tron to artistic GPS projects like Paula Levine's San Francisco $\Leftrightarrow$ Baghdad and Jeremy Wood's GPS drawings-this paper points to two key issues for the intersection of surveillance and games. First, I argue that games can creatively misuse surveillance technologies as a form of resistance. Second, such creative misuse creates a particular embodied relationship to surveillance, what I term the "sensory-inscribed body." Ultimately, the sensory-inscribed body, through creative misuse of locative tracking technologies, demonstrates that surveillance space is not statically inscribed with meaning; instead, the meanings emerge through practice. Playful engagement reinscribes the possible meanings, positioning the embodied player not simply as an object of surveillance but instead as a creative misuser who brings together heterogeneous elements to reconfigure spatial relationships between people and surveillance technologies.
\end{abstract}

\section{Introduction}

Joshua grabbed his smartphone and ran out of the room. The Glympse app was running on his phone and, as it traced his every move, it left a trail of his path as he headed to the open, grassy mall at the University of Maryland, College Park (see Figure 1). His teammates sat together in a close group with laptops and smartphones, watching him run on their screens, noting his speed in miles per hour, and attempting to discern the shapes he was making with his movements. Soon a letter emerged from his trace, charted out by the GPS antenna in his smartphone tracking his movement in a very precise way. Joshua ran around the campus to spell out the letters of a word. Once his teammates figured out the three-letter word (aptly, "RUN"), they brought the word to the game moderator. They correctly detected the word spelled out through Joshua's traces across the campus and were given the location of a hidden flag in a nearby building. They texted the information to Joshua. The team then watched him sprint for the building, retrieve the flag, and sprint back to the game central. As he ran into game central with the flag, he realized that his team had narrowly beaten a team comprised of university athletes, who entered the room just moments after he stepped through the door.

I designed the game - titled The Amazing Race with Glympse - alongside my students in an attempt to creatively misuse a location-aware surveillance technology for playful purposes. Glympse is not intentionally a gaming platform; instead, the company markets its product as way to share your real time location with friends or colleagues, a form of "participatory surveillance" (Poster 1990: 69; Albrechtslund 2008). On the company's homepage, they highlight three uses: for letting people at work know where you are when you're running late, for gathering with friends when evening plans change the meeting location, or for tracking a teen driver to make sure they don't speed and arrive at their destination safely. Using 
Glympse as a gaming platform situates it among a long line of artistic projects and games that creatively misuse mobile and locative tracking technologies. In so doing, this game enacted the embodied tension over location-based privacy and the practice of participatory surveillance. As such, the game performed issues of visibility, embodied awareness, and resistance through playful purposes.

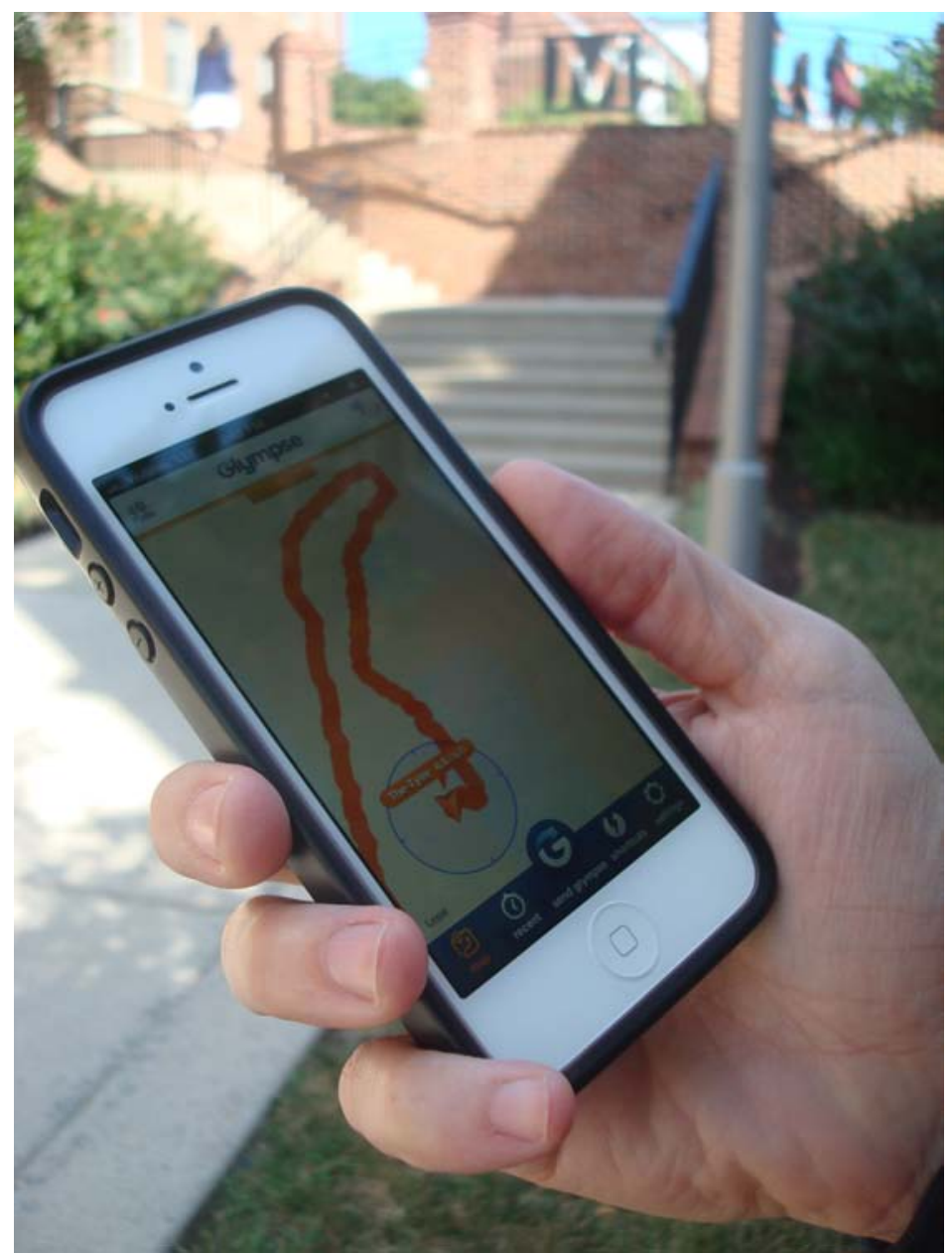

Figure 1: Joshua's phone running the Glympse app during gameplay for The Amazing Race with Glympse on the University of Maryland campus. () 2013 Jason Farman.

Using The Amazing Race with Glympse and the projects that inspired the game as my main examplesfrom games such as geocaching and GPS::Tron to artistic GPS projects like Paula Levine's San Francisco $\Leftrightarrow$ Baghdad and Jeremy Wood's GPS drawings - this paper points to two key issues for the intersection of surveillance and games. First, I argue that games can creatively misuse surveillance technologies as a form of resistance. Second, such creative misuse creates a particular embodied relationship to surveillance, what I term the "sensory-inscribed body."

\section{Locative Surveillance}

A mode of surveillance that is increasingly in the public imaginary (and in the writings of tech magazines and academics alike) is location-based tracking. Concerns over locative surveillance came to the fore in April of 2011 when it was discovered that the iPhone kept a record of the device's latitude and longitude, sometimes up to a year's worth of data, without the user's consent. The device stored this information on a user's computer when the iPhone was synched with a laptop or desktop computer. Pete Warden, one of the researchers who discovered the hidden tracking code running on the iPhone, noted, "Apple has made it 
possible for almost anybody — a jealous spouse, a private detective-with access to your phone or computer to get detailed information about where you've been" (Arthur 2011).

Location-aware tracking via mobile phones, however, can be linked back to the emergence of the Enhanced 911 (E911) systems that were able to detect the location of the caller. As Adriana de Souza e Silva and Jordan Frith note,

The E911 system was widely accepted as necessary, but privacy advocates immediately raised concerns about who could access mobile phones' location. . . . A major difference, however, from early location tracking systems such as E911 and the current LBS [location-based services] is that with E911 location was disclosed to emergency services to increase safety and security. With most commercial LBS, location is traded for convenience, entertainment, and profit.

(de Souza e Silva and Frith 2012: 119)

Information about the specifics of a person's location has, especially in the age of mobile media, often triggered concerns over privacy and unwanted uses of surveillance (i.e., participatory surveillance taken out of its intended context and delivered to an audience different from that which the person intended). This is highlighted by websites like Please Rob Me, which pulled public data from Foursquare and Twitter to expose who was on vacation, what they had recently purchased, and where they lived. The aim of the site, as Jennifer Van Grove notes, is not only to "raise a few eyebrows" but to also "make us more aware" (Van Grove 2010). Two years after the launch of Please Rob Me, an app was released called Girls Around $M e$, which used the same data to tell users which women had recently checked-in nearby. As Nick Bilton described, "Once you identify a woman you'd like to talk to, one that inevitably has no idea you're snooping on her, you can connect to her through Facebook, see her full name, profile photos and send her a message" (Bilton 2012). The app, which was launched in March of 2012 (and was taken down from the Apple App store in the same month), removes locational information from its intended audience and context. Thus, examples like Please Rob Me and Girls Around Me show that locative privacy is contextual rather than a clearly defined notion (as it has always been). Taken out of its context, information posted by people on locative social networks like Foursquare becomes surveillance tools that are seen as violations of personal privacy.

Christian Licoppe and Yoriko Inada discuss an early example of such perceived threats of location disclosure in their article about player behavior in the Japanese game Mogi. The game, which was launched in 2003 in Japan, "consists in collecting virtual objects with a mobile phone. These are 'localized' (in the sense that users can act on them only when they are close to their virtual position)" (Licoppe and Inada 2006: 42). The game interface situates the player in his or her real-time location and visualizes the virtual objects nearby and the other players who are within a 500-meter radius. Players' responses to coming into close contact with other players (typically strangers) were varied and tended to demonstrate the player's attitude about the relationship between location and privacy. As Licoppe and Inada describe, players who are in proximity to one another generally exchange pleasantries via in-game text message such as "We seem to be on the same train," and "I am going to look for you...In which compartment are you?" but rarely followed through on meeting. These pleasantries maintain cultural decorum while achieving a degree of anonymity that offsets the potential dangers of meeting a stranger. More extreme variations on this kind of encounter would occasionally be seen when a player would turn off the game if another player was about to coincide with their location.

Yet, people are increasingly sharing location-based information in their games and with their social networks. "Location" fits among other data as information that reveals something unique about a person's identity; it is thus a key element for a player's actions in locative games and is becoming a dominant aspect shared by people with their social networks. These modes of participation and gameplay extend 
into gamified locative social networks such as Foursquare, which encourage check-ins to various locations through a rewards systems that offer badges and mayorships. For example, in 2010, just over a year after the launch of Foursquare, 26 per cent of people using these kinds of locative social games/networks were checking in to locations every hour (Perez 2010). By selectively curating the locative information distributed to their network, users engage a particular mode of participatory surveillance that reiterates their perceived "presentation of self." de Souza e Silva and Frith note:

The development of location-based mobile phones added a new layer to one's digital presentation of self: location. This layer is enacted through location-based social networks (LBSNs) like Loopt and Gowalla, and location-based mobile games (LBMGs) like Foursquare, Mogi, and Botfighters. By choosing to check in to some places and not others, LBSN participants show their social network some aspects of their lives and not others. Those locations, then, become part of their "presentation of self," a term made famous by Erving Goffman.

Expanding on Nick Kaye's thesis that "the meanings of utterances, actions and events are affected by their 'local position,"' so too is the practice of participatory surveillance and the presentation of self through locative games (Kaye 2000: 1). For Larissa Hjorth, location sharing is central not only to everyday spatial practices of mobile users, but also to the mobile games that weave themselves into the spaces of the everyday. As location is emphasized as a primary mode of information and interaction, notions of privacy, location, and participation become foundational elements that inform the acts of gameplay. She writes, "Through the first generation of urban mobile games over the past decade, cartographies of place have been infused by the migration of different notions of co-presence. . . . Such phenomena raise questions about the cultural specificity of notions like privacy and what constitutes 'participation"" (Hjorth 2011: 367-368). Being a participant in locative games and social networks requires players to engage in the participatory surveillance of locative information, tracking the places that each person shares as he or she moves through everyday spaces.

\section{Creative Misuse and Locative Games}

Tracking a person's location using GPS has characterized the practices of those such as the FBI attaching GPS trackers to peoples' cars to concerned parents who buy devices that attach to their child's shoe and track their location (see Marx and Steeves 2010). The American Civil Liberties Union (ACLU) notes, "As a result [of these new tracking technologies], government officials can learn a tremendous amount of detailed personal information about you by accessing your location history ranging from which friends you're seeing to where you go to the doctor to how often you go to church. Law enforcement can get months' worth of this information, without you ever knowing - and often without a warrant from a judge" (ACLU n.d.).

Since the launch of the GPS satellites by the United States military in the mid-1970s and the earlier launches of satellites by the Soviet Union in the late-1950s and the U.S. in the 1960s, there has always been a sense that these satellites would be extraordinarily useful for surveillance. Soon after the launch of Sputnik by the Soviet Union in October of 1957, the United States "covertly accelerated its plans to develop a reconnaissance satellite" (Arnold 2005: 7). A decade later, with these reconnaissance satellites successfully in place, President Lyndon Johnson said, "Because of satellites, I know how many missiles the enemy has" (Arnold 2005: 7).

Such surveillance systems - as Aaron Martin, Rosamunde van Brakel, and Daniel Bernhard note in their article, "Understanding Resistance to Digital Surveillance"-are typically understood in relationship to the kinds of resistance that are formed in response (Martin, van Brakel, and Bernhard 2009). It could be 
argued that resistance to surveillance actually functions as a co-constitutive feature of the implementation of surveillance systems. That is, in order for us to engage surveillance, such engagements must already understand the potential to subvert the intentions of system. Martin, van Brakel, and Bernhard argue, "Yet resistance is not merely an epiphenomenon of surveillance - it is a basic and necessary co-development of surveillance, existing in many forms that often go unrecognized" (2009: 216).

An important case in point is seen in locative GPS games. Soon after the U.S. government removed "Selective Availability" (SA) to highly accurate GPS signals on May 1, 2000, civilian users began experimenting with these broadly available and accurate signals. Two days after SA was removed, David Ulmer placed the first geocache container in the Portland, Oregon area. This was the start of the GPS treasure hunting game called Geocaching (which currently has over four million registered players, growing at a rate of around 2,500 players a day) (see Farman 2012: 83-84). There are currently over 1.2 million geocaches hidden around the world (including Antarctica) and some regions are so densely populated with caches that players can find one every 0.1 mile (the minimum distance caches can be placed apart from one another).

Geocaching, from its very inception, was a ludic response to a system that was largely understood as a surveillance and tracking system. Such a redefinition in the imagined uses and daily practices of a technology is what I like to call "creative misuse." Extending the creative misuse of geocaching, artist Paula Levine designed a geocaching project that exemplifies such a refashioning of GPS. Her project, titled San Francisco $\Leftrightarrow$ Baghdad, began by overlaying a map of the bombing sites in Baghdad during the first Gulf War on top of a map of San Francisco (see Figure 2 below). Where these two maps coincided in her home city of San Francisco, Levine placed a geocache container that held a list of military personnel who had been killed in the war. Utilizing the U.S. military's GPS system as a means to critique the U.S. military's actions abroad functions as a tactic of resistance; a creative misuse that reimagines forms of resistance by utilizing the tools at hand through gaming (see Levine 2013).

In conjunction with the gameplay of geocaching being a creative misuse of tracking technology, the gameplay is also highly contextualized by the understanding of being potentially watched. From the use of the term "muggles" for non-players around the geocacher-who should not be alerted to the fact that there is a geocache container nearby (or that you're hiding a geocache container) - to the fear that gameplay may be misconstrued as a potential act of terrorism (e.g. planting a bomb), surveillance and resistance to surveillance are coded into the gameplay. In 2008 in downtown Auckland, a geocacher was spotted by CCTV cameras and his actions were read as "placing a bomb." Subsequently, sections of the city were closed down as the bomb squads moved in to investigate the device (a circular Tupperware container painted black for camouflage).

My own experiences as a geocacher shed light on the relationship between surveillance and gameplay in locative games like geocaching. I first began geocaching in 2009 in Eastern Washington State, which is largely rural farmlands and high desert. Sagebrush offers great hiding spots for many geocaches in Eastern Washington and in the area I lived there was such a thriving geocaching community that I could walk a mile and find ten geocaches. This was my baseline for what gameplay in geocaching looked like. In the fall of 2009, five months after I began geocaching, I spent several weeks in the UK and geocached while I was there. Soon after checking in to my hotel in London, I walked outside to hunt for a nearby geocache. After less than five minutes of searching, I abandoned hopes of looking for the container because there were three CCTV cameras pointing in my direction. The extensiveness of surveillance cameras in London shifted the concept of muggles away from non-players to devices that recorded your movements. Thus, while being surveilled is a common characteristic of gameplay for geocaching, who is watching (or what is watching) and how it is read varies greatly from game site to game site. This process of inscribing a gamer via surveillance is something I'll focus on more extensively at the end of this article. 


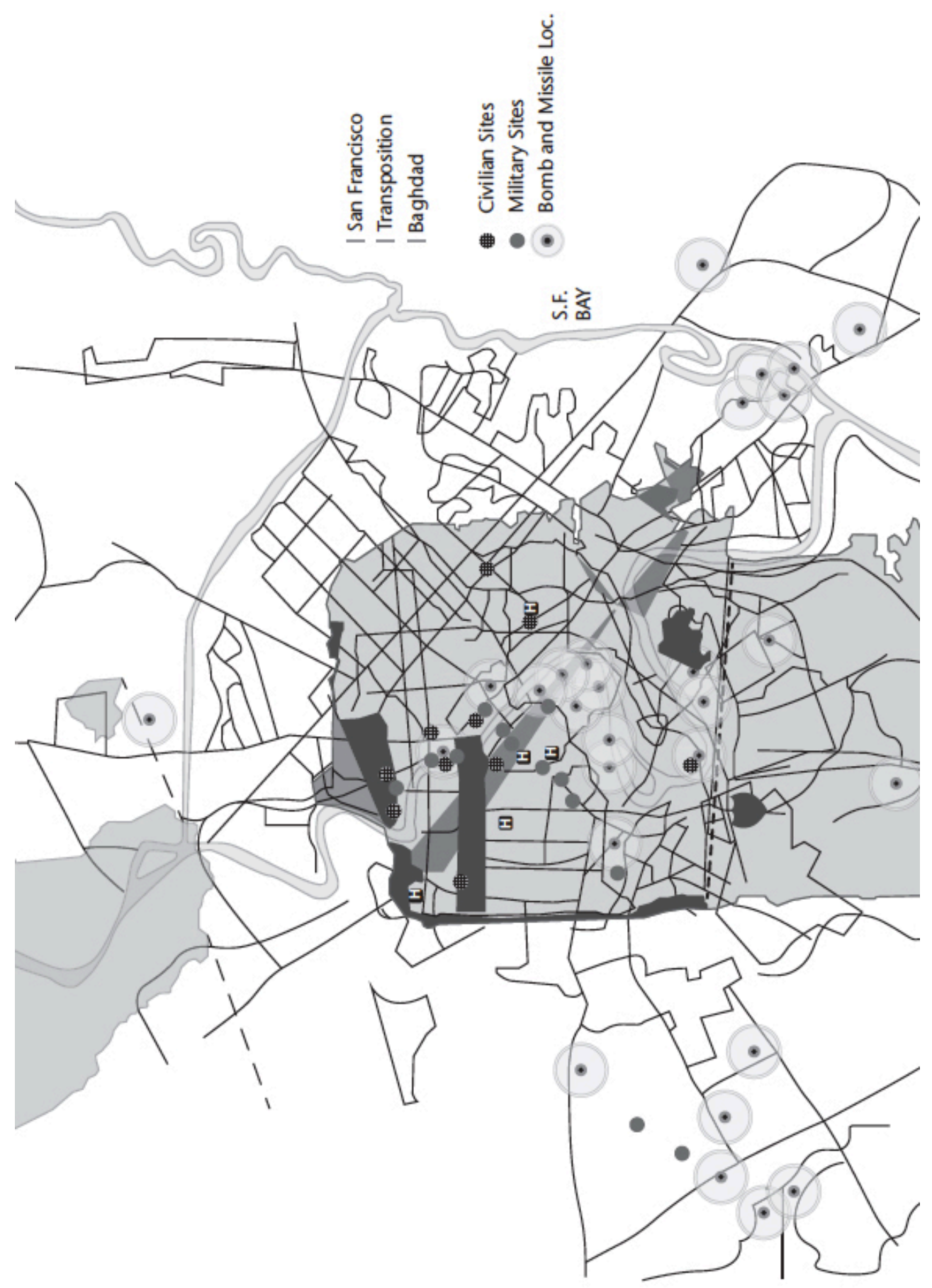

Figure 2: The map of Paula Levine's San Francisco $\Leftrightarrow$ Baghdad project, showing the overlay of Baghdad onto San Francisco. The dots are the locations of bombing sites in Baghdad. At these sites, Levine placed a geocache container with a list of military personnel who had been killed in the war. (c) 2010, Paula Levine, http://shadowsfromanotherplace.net.

While geocaching is a creative misuse of tracking technologies, it is also a response to being tracked (and an embodied challenge to the cliché that "If you're not doing anything wrong, why should you worry about being surveilled?"). Another gaming example of creatively misusing GPS tracking was GPS::Tron, launched in 2004 by Thomas Winkler (Figure 3). GPS::Tron utilizes a cell phone that is connected-via 
Bluetooth - to an external GPS receiver (GPSr) and has players' traces create an experience based on the light bike scene from the 1982 film Tron. In the film, players are trapped inside a video game computer system and are forced to battle each other through various tournaments including a "light bike" racing game. This racing game sets two players side-by-side on a digital grid, each driving a different colored vehicle. The players begin driving forward, leaving in their path a digital trail of their vehicle's color. This trail forms a wall that neither player can cross again, thus making the goal of the game to trap the other player within the digital walls created by the vehicles. In GPS::Tron, both players' vehicles take on a specific color and they begin movement side-by-side on the GPS interface. The vehicles, however, do not necessarily need to be physically next to each other for the game to work. One player can begin the game on the streets of Los Angeles while the opponent begins the game on the streets of Sydney. Their locations are mapped onto the digital representation of their vehicles on the GPS interface, allowing players from around the globe to compete with each other.

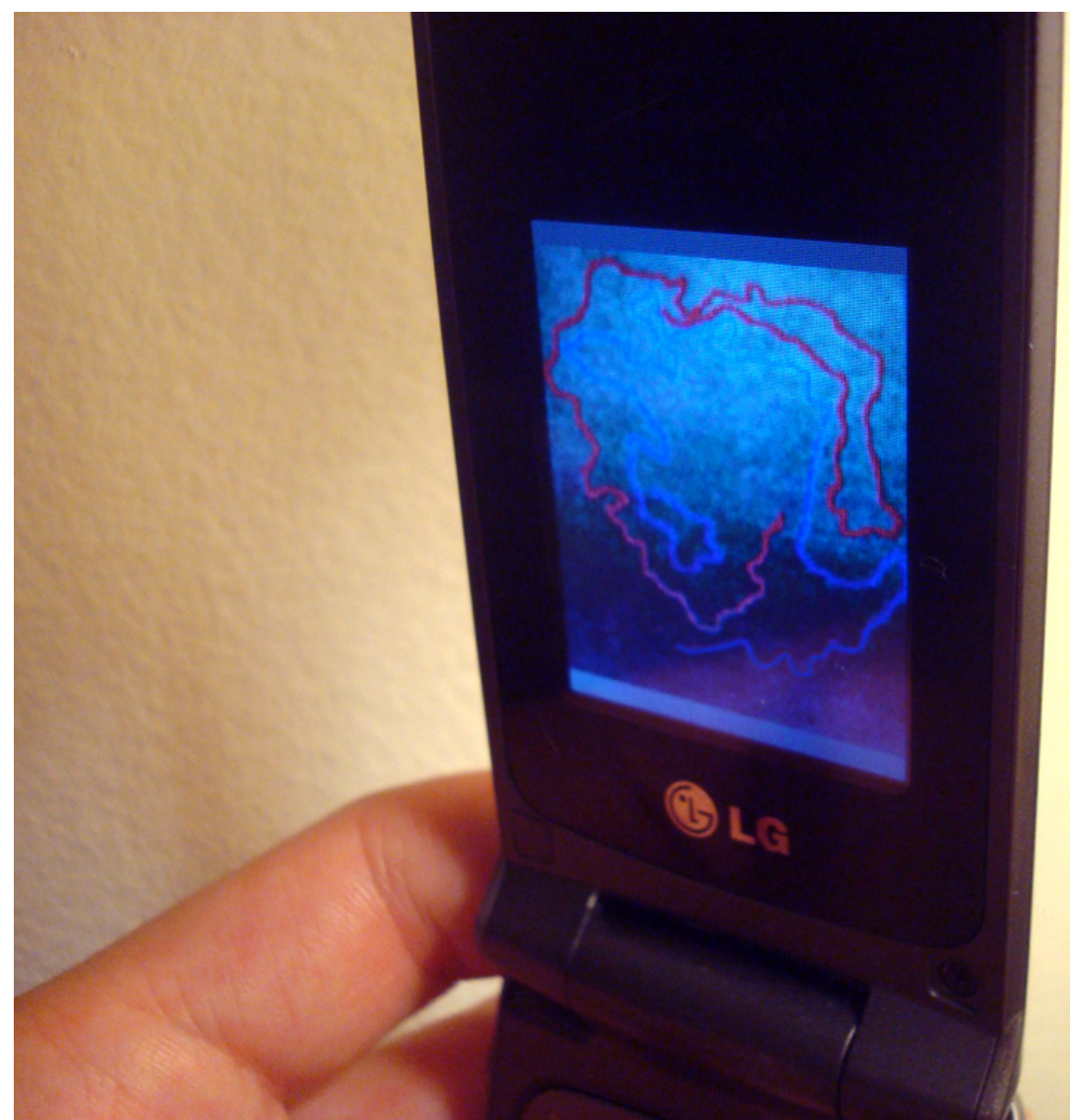

Figure 3: A Bluetooth-enabled feature phone running GPS::Tron. The two players leave traces (red and blue) as they move throughout their respective locations with the hopes of creating an impassable wall with their trail. (C) 2013 Jason Farman.

In GPS::Tron-which won the Golden Nica award at the ARS Electronic Festival in 2004-as a player moves forward 200 meters, their position on the GPS interface moves forward one centimeter. As players navigate the city streets, the interface of the windshield works collaboratively with the interface of the GPS, combining the material world with the digital representation of that world through the singular conception of the "interface."

This kind of playful use of GPS traces is familiar territory for many conceptual and site-specific artists, such as Jeremy Wood, whose GPS drawings sketch out images and words across the entire length of cities or open spaces. For example, his project Meridians uses GPS to draw a quote from Moby Dick across a 
vast space: "It's not down in any map; true places never are." The traces span 458.6 miles of traveled distance that produced a 44.2-mile phrase (Lauriault 2009: 361). As Tracey P. Lauriault writes about Wood's GPS drawings, "Line quality reflects the nature of the built environment and the placing of physical objects, the scale of open spaces, the historical meaning of the local, and elucidates literal and metaphorical spatial conundrums such as the discrepancies between local and global models and what it means to actually be somewhere" (Lauriault 2009: 361). Wood's creative misuse of GPS performs the tension between being tracked from an overhead perspective (and the visualization of that trace) and the lived experience of traversing that same space. Thus, while GPS offers a perspective of space - what may be misunderstood to be an objective point-of-view since it is a machine eye rather than a human eye that is doing the surveilling (see Farman 2010) - Wood's drawings take those traces and emphasize the lived body's movements and experience (i.e., the production of "local" space). The projects can, within this lens, be understood as functioning as a critique of the objective spaces produced by GPS. Tracking technologies utilizing GPS offer a limited understanding of lived space, which is always being produced by people who are shaping the meaning of a built environment and a landscape. As Marc Tuters and Kazys Varnelis argue, "in adopting the mapping-while-wandering tactics of the derive, tracing-based locative media suggest that we can re-embody ourselves in the world, thereby escaping the prevailing sense that our experience of place is disappearing in late capitalist society" (Tuters and Varnelis 2006: $359)$.

To take a technology and creatively misuse it allows for gamers, artists, and observers to reimagine the ways that space is given meaning. Locative games use this as their core tenant. They reimagine what a space means and how a technology can ultimately give new meaning to a space, especially when that technology is used in ways that run counter to the initial intentions of the medium's designers. These practices - creatively misusing a technology and reimagining the meaning of a space-are acts of resistance to the dominant modes of spatial production.

The notion of creative misuse builds on Rita Raley's sophisticated theorization of the term "tactical media," a term that points toward alternative media practices that prioritize "micropolitics of disruption, intervention, and education" (2009: 1). The term was coined in the mid-1990s to apply Michel de Certeau's ideas about "tactics" (as modes of resistance) to practices with emerging media (see Garcia and Lovink 1997). David Garcia and Geert Lovink's article, "The ABC of Tactical Media," note that "[de Certeau] shifted the emphasis from representations in their own right to the 'uses' of representations. In other words how do we as consumers use the texts and artifacts that surround us. And the answer, he suggested, was 'tactically'. That is in far more creative and rebellious ways than had previously been imagined" (1997). Creative misuse is a mode of tactical media practice: they are both "aesthetic and critical practices that have specifically emerged out of, and in direct response to, both postindustrial society and neoliberal globalization" (Raley 2009: 3). Both categories are "not meant to be either fixed or exclusive. If there were one function or critical rationale that would produce a sense of categorical unity, it would be disturbance" (Raley 2009: 6).

Creative misuse as a challenge to surveillance is also founded on a practice of bricolage-as-resistance. Jacques Derrida, expanding the work of Claude Levi-Strauss, describes this process as done by a bricoleur, "someone who uses 'the means at hand,' that is, the instruments he finds at his disposition around him, those which are already there, which had not been especially conceived with an eye to the operation for which they are to be used and to which one tries by trial and error to adapt them, not hesitating to change them whenever it appears necessary, or to try several of them at once, even if their form and their origin are heterogeneous" (Derrida 1978: 285). Similar to Martin, van Brakel, and Bernhard's notion of ad hoc resistance (Martin, van Brakel, and Bernhard 2009: 217), this form of bricolage-as-resistance brings together heterogeneous elements in unexpected ways and thus produce a new way of seeing and interacting with familiar objects like surveillance technologies. Such practices resonate with practices of tactical media as countermeasures to established systems. The established 
systems - or "strategies" in de Certeau's terms - assume that "a place can be circumscribed as proper and thus serve as the basis for generating relations with an exterior distinct from it" (de Certeau 1984: 69). Tactics instead insinuate themselves "into the other's place, fragmentarily, without taking it over in its entirety" (de Certeau 1984: 70). He goes on to argue, "This is achieved in the propitious moments when they are able to combine heterogeneous elements . . . the intellectual synthesis of these given elements takes form, however, not of a discourse, but of the decision itself, the act and manner in which the opportunity is 'sized"' (de Certeau 1984: 70).

All forms of resistance that don't seek to "take over a system in its entirety" (i.e., approaches that don't seek to simply replace a hierarchical and binary system with another hierarchy and similar binary between those in power and those without power) function within the logic of bricolage-as-resistance. Finding modes of resistance to surveillance does not require a dismantling of the system since such acts would likely fill the vacuum with new modes of surveillance operated by new figures in power; instead, revolutionary countermeasures to surveillance take the tools that are at hand and creatively misuse them. Such resistance to surveillance brings together the tools of surveillance and the tools of the culture to form unexpected partnerships that ultimately reconfigure the ways surveillance is understood and practiced.

Creative misuse, similar to many modes of tactical media, are "never perfect, always in becoming, performative and pragmatic, involved in a continual process of questioning the premises of the channels they work with" (Garcia and Lovink 1997). Accordingly, many acts of creative misuse are coopted by the very structures they seek to disrupt. Various modes of creative misuse in gaming (from patches and mods, to cheating and disruptive playfulness that works counter to the game's dominant modes of play) can eventually become part of the standard practices of play as gaming companies appropriate tactical practices into their strategic approach to game design. In locative games, as Lee Humphreys notes, players are "doing the work of an interactive surveillance society" for corporations like Google (Humphreys 2011: 584). Citing the example of Dodgeball, the locative social network started by Dennis Crowley before he sold it to Google and eventually launched Foursquare, she writes that, "by participating in an interactive system where one's behaviors and interactions are mediated through a central server that can then be linked to other databases, [the player's] participation on Dodgeball feeds into what Andrejevic has termed the 'digital enclosure,' 'an interactive realm wherein every action and transaction generates information about itself"' (2011: 583). Such self-generating information leads to gameplay that is simply labor for corporations like Google, producing location-specific information for a company that markets its mission (according to its "About" page) as organizing the "world's information and make it universally accessible and useful."

However, following Garcia and Lovink, "Our hybrid forms are always provisional. What counts are the temporary connections you are able to make. Here and now, not some vaporware promised for the future" (Garcia and Lovink 1997). These provisional forms of creative misuse in games may eventually be appropriated; however, tactics and strategies always exist in a back-and-forth that comes to define them. Creative misuse as resistance allows for this interplay, continually employing tactics that expose these appropriations as dependent on the category of the disruptor; that is, the disruptor and the appropriator exist in a dialectical relationship. Following Alexandre Kojève's reading of Hegel's master/slave dialectic, the appropriator's very identity depends on the existence of the disruptor (see Kojève 1969: 3-30). Agency, especially the agency to cause change, resides in the realm of the disruptor who can challenge the status quo. "Thus man the player," as Celia Pearce argues, "is also man the creator, who plays with, subverts, and reconfigures media, inscribing it with new goals and cultural meanings" (Pearce 2009: 279).

\section{The Sensory-Inscribed Body at Play}

An important feature of creative misuse is the ways that it creates particular experiences of embodiment, especially when implemented in locative games. Returning to my first example of The Amazing Race with 
Glympse, the "runners" like Joshua whose role it was to spell out large letters (à la Jeremy Wood) were initially surprised at how accurately they were monitored by Glympse. I had the players test out the system before they attempted to spell out letters with the app and, upon their return, the common phrase was, "I can't believe how precisely it tracks me!"

As Ingrid Richardson has argued, "every human-technology relation is also a body-tool relation and, as such, every merger with technology invokes certain kinds of being-in-the-world, and particular ways of knowing and making that world" (Richardson 2010: 432). Such being-in-the-world, through creatively misusing a GPS tracking technology for playful purposes, happens on several levels. To account for the multi-layered practice of the body in locative games, I argue for what I term the "sensory-inscribed body." The sensory-inscribed body is simultaneously produced through the senses and through the cultural inscriptions both written on and written by the body. For example, when the players took their devices outside to test the GPS capabilities of Glympse, they at once experienced their movement through space (their speed, the proprioceptive experience of understanding their own position in the world and the body's relationship to other people and objects, seeing themselves represented on the screen as they moved, the way the phone felt in their hands, the sounds of the space, to name a few of the sensory things they encountered) and they experienced the ways that their bodies were read. This inscribing/reading of the body happens in the ways that they are interpreted by others - from being read as a "phone zombie" who is focused on his or her device and not paying attention to the world around them or as a person of privilege who can afford a smartphone - and they are also inscribed by the technology. They are being tracked by their GPSr's interpretation of GPS signals. They are located and leave an inscription in the form of their trace. While the technology may be utilized to inscribe a particular body in any number of ways (from gamer to terrorist), the body of the players here also inscribes by leaving traces and by inscribing other people within the space (from non-player to obstacle).

The sensory-inscribed body is important for my theorization of creative-misuse and resistance because the pairing of tracking tools and games produces a distinct sense of self in relationship to surveillance spaces. Since all spaces are produced alongside the simultaneous production of embodiment - and thus, as Henri Lefebvre has argued, bodies and spaces are mutually dependent (Lefebvre 1991: 170) - then surveillance space and the bodies that interact with those technologies are continually inscribing the meaning of both categories.

The sensory-inscribed body thus signals several things for the intersection of surveillance and games. First, with participatory surveillance technologies like Glympse, the sense of self is always in relationship to the larger network of people and the real time location of those in the network. This "social proprioception" of knowing one's position in relationship to the positions of others in a network produces a sensory engagement with space that expands it beyond the immediate locale to give the person a larger sense of spatial connectivity. As the players run, they are aware of being watched by their teammates back at game central and they can, if they choose, track the movements of the other runners in the game. As they do so, there is also a sense of proprioception with the tracking technology itself as a player moves into view of satellites and waits for confirmation of his or her location (as the dot representing the player gets accurately positioned by GPS). As this is happening, there is a sense of creating an embodied clear line-of-site between the smartphone and the GPS satellites that triangulate the player's position.

Second, the players understand that they are being inscribed in many ways, both by their teammates (who are literally trying to "read" the player's bodily movements) and the bystanders who observe them running in odd directions around the campus. However, most relevant to my arguments in this essay, the players are aware of their own act of inscribing. Here, it is a re-inscribing of the purposes of a surveillance technology. They are giving new meaning to surveillance technologies through playful practices, an act that not only transforms the possibilities of a very familiar device like the smartphone, but one that can also reimagine how a body produces surveillance space. 
Third, sensory-inscription in locative games is enacted through networks of circulation: relationships between players, between players and nonplayers, between a player and his or her phone, between the phone and the GPS satellite, or between the software of the game and the rules that players can enact (or disrupt). Creative misuse performs the game as a network of relationships (in ways that resonate with Bruno Latour's Actor-Network Theory); however, it is important to note that sometimes the sensoryinscribed body in these game networks is enacted at the player-to-player level and sometimes it is machine bodies interacting with other machine bodies. Sensory-inscription goes further to also include modes of inscription that account for the writing practices of game rules, cultural constructions, infrastructures, social mores, spatial formations, and digital code, to name a few. That is, to understand the player's performance of creative misuse within the lens of the sensory-inscribed body, we must account for the nonhuman bodies and various objects in the world (both physical and virtual) that create the network of the game. As Ian Bogost thoughtfully argued in his 2009 keynote at the Digital Games Research Association Conference, "Such a perspective invites a surprising truth: game studies means not just studies about games-for-players, or as rules-for-games, but also as computers-for-rules, or as operational logics-for computers, or as silicon wafer-for-cartridge casing, or as register-for-instruction, or as radio frequencies-for-electron gun. And game is game not just for humans but also for processor, for plastic cartridge casing, for cartridge bus, for consumer, for meme carrier, and so on" (Bogost 2009). Creative misuse, via the sensory-inscribed body, happens among these networks of circulation, networks that allow a game to not only be played but to also be misused. These networks are always being produced and, never being settled, allow for new formations between nodes in the network at any time.

Ultimately, the sensory-inscribed body, through creative misuse of locative tracking technologies, demonstrates that surveillance space is not statically inscribed with meaning; instead, the meanings emerge through practice. Playful engagement reinscribes the possible meanings, positioning the embodied player not simply as an object of surveillance but instead as a creative misuser who brings together heterogeneous elements to reconfigure spatial relationships between people and surveillance technologies.

\section{References}

ACLU. n.d. Government Location Tracking: Cell Phones, GPS Devices, and License Plate Readers. https://www.aclu.org/government-location-tracking-cell-phones-gps-devices-and-license-plate-readers

Albrechtslund, Anders. 2008. Online Social Networking as Participatory Surveillance. First Monday 13 (3). http://firstmonday.org/htbin/cgiwrap/bin/ojs/index.php/fm/article/viewArticle/2142/1949

Arnold, David Christopher. 2005. Spying from Space: Constructing America's Satellite Command and Control Systems. College Station, TX: Texas A\&M University Press.

Arthur, Charles. 2011. iPhone Keeps Record of Everywhere You Go. The Guardian April 20, 2011. http://www.theguardian.com/technology/2011/apr/20/iphone-tracking-prompts-privacy-fears

Bilton, Nick. 2012. Girls Around Me: An App Takes Creepy to a New Level. New York Times. March 30, 2012. http://bits.blogs.nytimes.com/2012/03/30/girls-around-me-ios-app-takes-creepy-to-a-new-level/? r=0

Bogost, Ian. 2009. Videogames are a Mess. http:/www.bogost.com/writing/videogames are a mess.shtml

de Certeau, Michel. 1984. The Practice of Everyday Life. Los Angeles: University of California Press.

de Souza e Silva, Adriana and Jordan Frith. 2012. Mobile Interfaces in Public Places: Location Privacy, Control and Urban Sociability. New York: Routledge Press.

de Souza e Silva, Adriana and Jordan Frith. 2013. Re-Narrating the City Through the Presentation of Location. In The Mobile Story: Narrative Practices with Locative Technologies, edited by Jason Farman, 34-49. New York: Routledge Press.

Derrida, Jacques. 1978. Writing and Difference. Translated by Alan Bass. Chicago: University of Chicago Press.

Farman, Jason. 2010. Mapping the Digital Empire: Google Earth and the Practice of Postmodern Cartography. New Media \& Society 12 (6): 869-888.

Farman, Jason. 2012. Mobile Interface Theory: Embodied Space and Locative Media. New York: Routledge Press.

Garcia, David and Geert Lovink. 1997. The ABC of Tactical Media. Nettime post, May 16, 1997. http://www.nettime.org/ListsArchives/nettime-1-9705/msg00096.html

Hjorth, Larissa. 2011. Mobile@game Cultures: The Place of Urban Mobile Gaming. Convergence 17 (4): $357-371$.

Humphreys, Lee. 2011. Who's Watching Whom? A Study of Interactive Technology and Surveillance. Journal of Communication 61 (4): 575-595.

Kaye, Nick. 2000. Site-Specific Art: Performance, Place and Documentation. New York: Routledge.

Kojève, Alexandre. 1969. Introduction to the Reading of Hegel: Lectures on the Phenomenology of Spirit. New York: Basic Books. 
Lauriault, Tracey P. 2009. GPS Tracing - Personal Cartographies. The Cartographic Journal 46 (4): 360-365.

Lefebvre, Henri. 1991. The Production of Space. Translated by Donald Nicholson Smith. Oxford: Blackwell Publishing.

Levine, Paula. 2013. On Common Ground: Here as There. In The Mobile Story: Narrative Practices with Locative Technologies, edited by Jason Farman, 143-158. New York: Routledge Press.

Licoppe, Christian and Yoriko Inada. 2006. Emergent Uses of a Multiplayer Location-aware Mobile Game: the Interactional Consequences of Mediated Encounters. Mobilities 1 (1): 39-61.

Martin, Aaron K., Rosamunde E. van Brakel, and Daniel J. Bernhard. 2009. Understanding Resistance to Digital Surveillance: Towards a Multi-disciplinary, Multi-actor Framework. Surveillance \& Society 6 (3): 213-232.

Marx, Gary and Valerie Steeves. 2010. From the Beginning: Children as Subjects and Agents of Surveillance. Surveillance \& Society 7(3/4): 192-230.

Pearce, Celia. 2009. Communities of Play: Emergent Cultures in Multiplayer Games and Virtual Worlds. Cambridge, MA: The MIT Press.

Perez, Sarah. 2010. Study: Location-Based Services Users Are Passionate but Niche. New York Times, September 9, 2010, www.nytimes.com/external/readwriteweb/2010/09/09/09readwriteweb-study-location-based-services-users-are-pas83631.html

Poster, Mark. 1990. The Mode of Information: Poststructuralism and Social Context. Chicago: University of Chicago Press.

Raley, Rita. 2009. Tactical Media. Minneapolis: University of Minnesota Press.

Richardson, Ingrid. 2010. Ludic Mobilities: The Corporealities of Mobile Gaming. Mobilities 5 (4): 431-447.

Tuters, Marc and Kazys Varnelis. 2006. Beyond Locative Media: Giving Shape to the Internet of Things. Leonardo 39 (4): $357-$ 363.

Van Grove, Jennifer. 2010. Are We All Asking to Be Robbed? Mashable February 17, 2010. http://mashable.com/2010/02/17/pleaserobme/ 